\title{
Adrenarche and Skeletal Maturation during Luteinizing Hormone Releasing Hormone Analogue Suppression of Gonadarche
}

\author{
Margaret E. Wierman, Donna E. Beardsworth, John D. Crawford, John F. Crigler, Jr., M. Joan Mansfield, \\ Hans H. Bode, Paul A. Boepple, David C. Kushner, and William F. Crowley, Jr. \\ Reproductive Endocrine Unit, Vincent Research Laboratories, and the Medicine, Gynecology and Children's Services \\ of the Massachusetts General Hospital, the Childrens Hospital, and the Departments of \\ Medicine and Pediatrics, Harvard Medical School, Boston, Massachusetts 02114
}

\begin{abstract}
During puberty the effects of adrenal androgens upon skeletal maturation are obscured by the influence of gonadal steroids. Suppression of gonadarche with an analogue of luteinizing hormone releasing hormone (LHRHa) affords an opportunity to examine the onset and progression of adrenarche in the absence of pubertal levels of gonadal steroids in a controlled fashion and to explore the relationship between adrenal androgens and the rate of epiphyseal maturation.

In 29 children with central precocious puberty, gonadarche was suppressed with LHRHa adminstration for 1-4 yr. During LHRHa exposure, dehydroepiandrosterone sulfate (DHAS) levels, as an index of adrenal maturation, were constant or increased in an age-expected manner. The change in bone age for change in chronologic age decreased from $1.7 \pm 0.1$ to $0.49 \pm 0.05$ $(P=0.00005)$, indicating that the LHRHa-induced return to a prepubertal gonadal steroid environment was associated with a slowing of skeletal maturation. DHAS levels were correlated with the rate of skeletal advancement before $(r=0.57, P$ $=0.001)$ and during 12 to $48 \mathrm{mo}$ of exposure to LHRHa (r $=0.52, P=0.003)$. A negative correlation of DHAS values with subsequent increases in predicted mature height was observed $(r=-0.49, P=0.007)$.

Thus, in children with central precocious puberty, adrenarche progressed normally during LHRHa suppression of gonadarche. In children with the onset or progression of adrenarche during maintenance of a prepubertal gonadal steroid milieu, there was less evidence than in preadrenarchal children of a restraint upon skeletal maturation. These data suggest that adrenal androgens contribute importantly to epiphyseal advancement during childhood.
\end{abstract}

\section{Introduction}

The ontogeny of adrenal androgen secretion and the impact of the adrenal androgens upon skeletal maturation in childhood has been difficult to study due to the overshadowing effects of gonadal steroids at puberty. Experiments of nature in which the onset of adrenarche and gonadarche are dissociated have suggested that these two processes are independently controlled (15 ). It has not been possible previously to examine the progression

Address reprint requests to Dr. Crowley, Reproductive Endocrine Unit, Massachusetts General Hospital.

Received for publication 19 March 1985 and in revised form 24 September 1985 .

J. Clin. Invest.

(c) The American Society for Clinical Investigation, Inc. $0021-9738 / 86 / 01 / 0121 / 06 \$ 1.00$

Volume 77, January 1986, 121-126 of adrenarche isolated from the influence of gonadal steroids, and to elucidate the relative contribution of adrenal androgens to the rate of bone maturation during childhood. With the advent of luteinizing hormone releasing hormone analogues (LHRHa), ${ }^{1}$ which block luteinizing hormone-releasing hormone (LHRH)-induced gonadotropin release selectively, it is now possible to investigate the role of spontaneously increasing levels of adrenal androgens during puberty in the absence of the complicating variable of changing levels of gonadal sex steroids. In this report, we have examined the onset and progression of adrenarche in 29 children with central precocious puberty (CPP) before and after the administration of a potent LHRHa (D-Trp6Pro9-NEt-LHRH), which previously has been shown to suppress pituitary gonadotropin secretion and to maintain gonadal steroids in the prepubertal range (6-9). Using this experimental model, we have been able to approach directly the natural history of the appearance of adrenal androgens as well as the impact of these hormones upon the rate of skeletal advancement and upon predicted height.

\section{Methods}

Patient population. 25 girls and 4 boys with CPP, manifested by premature secondary sexual development (earlier than age 8 in girls and age 10 in boys), and evidence of activation of the hypothalamic-pituitary-gonadal axis with pubertal levels of gonadotropins and sex steroids, were evaluated before and after continuous suppression of gonadarche with LHRHa. The initial evaluation occurred with a variable time after the onset of the premature gonadarche. Three of the girls and one of the boys had neurogenic precocity; all others had idiopathic precocity. To assess the timing of changes in long-term parameters such as skeletal maturation and adrenarche, only subjects whose puberty had been suppressed for a minimum of $12 \mathrm{mo}$ (range 12-48 mo) were selected for study (Table I).

Protocol. Base-line endocrine investigation included an assessment of patterns of secretion of gonadotropins with blood samples obtained at 20-min intervals for $4 \mathrm{~h}$ during the night (10 p.m.-2 a.m.) and the day (10 a.m.-2 p.m.). Serum levels of estradiol and dehydroepiandrosterone sulfate (DHAS) were determined on a morning sample. Testosterone levels were determined from pools of equal aliquots of night and daytime samples. A standard LHRH test was performed with a dose of $2.5 \mathrm{mcg} / \mathrm{kg}$ administered subcutaneously. Radiologic evaluation included a bone film of the left hand and wrist, adrenal and gonadal ultrasound examination, and cranial axial tomography.

After the base-line evaluation, all patients received the LHRHa in doses of 4-8 $\mathrm{mcg} / \mathrm{kg}$ per $\mathrm{d}$ as a subcutaneous injection. Outpatient followup included monthly blood samples for sex steroid levels and, in the girls, a vaginal smear for determination of a maturation index score. The children were readmitted at 3-6-mo intervals for follow-up studies

1. Abbreviations used in this paper: $\mathrm{BA}$, bone age; $\triangle \mathrm{BA}$, change in bone age; $C A$, chronologic age; $\triangle C A$, change in chronologic age; $C P P$, central precocious puberty; DHAS, dehydroepiandrosterone sulfate; LHRH, luteinizing hormone-releasing hormone; LHRHa, LHRH analogue(s). 
similar to the initial evaluation. Films to reassess bone maturation were obtained at 6-mo intervals.

Laboratory tools. Pubertal staging of breast and pubic hair development was quantitated by the method of Tanner (10). Testicular size was measured by a Prader orchidometer (11). Height was assessed by serial measurements with a wall-mounted stadiometer. Serum levels of gonadotropins, estradiol, and testosterone were assayed as previously described (12). DHAS values were measured using a direct radioimmunoassay of unextracted serum (13). There is cross-reactivity between DHAS $(100 \%)$ and dehydroepiandosterone $(40.5 \%)$, andosterone (32.6\%), androstenedione (18.8\%), and epiandrosterone (20.4\%); however, since DHAS levels are physiologically in the microgram per deciliter range and the other hormones are present in nanogram per milliliter amounts, there is no significant contribution of these steroids to the measurement of DHAS. A small contribution of their sulfated counterparts to DHAS values cannot be excluded. The normative data of Reiter et al. (14) were employed to assess the expected changes in DHAS levels with advancing chronologic age (CA). Bone films were read solely by Dr. Kushner employing the standards of Greulich and Pyle (15). Predicted adult heights were calculated using the tables of Bayley and Pinneau (16).

Statistical analysis. All results are expressed as mean \pm SEM. Statistical comparisons of clinical parameters, levels of adrenal androgens, and the rate of skeletal maturation before therapy and at $12(n=29), 18$, and $24(n=20) \mathrm{mo}$, as well as at the most recent admission (12-48 mo, $n$ $=29$ ) during continuous LHRHa administration, were performed using a $t$ test where applicable and a Wilcoxon Signed Rank test where the data were nonparametrically distributed. Linear regression analysis was employed to compare adrenal maturation, as reflected by changes in serum levels of DHAS, with the rate of bone advancement and increment in predicted mature height during LHRHa suppression of gonadarche.

\section{Results}

Base-line evaluation. During the base-line evaluation, each child demonstrated the clinical and endocrinologic features of centrally mediated gonadarche, including premature secondary sexual development, a pulsatile pattern of gonadotropin secretion, a pubertal response to LHRH administration, and an elevation of the gonadal steroid levels as previously reported (6-9). Secondary sexual characteristics by Tanner staging were as follows: in the 25 girls, breasts were at stage 2 in three, stages $2-3$ in two, stage 3 in eight, stages 3-4 in three, stage 4 in six, and stage 5 in three patients. In the girls, pubic hair was stage 2 in five, stage 3 in nine, stages $3-4$ in two, stage 4 in eight, and stage 5 in one girl. In the four boys, pubic hair was at stage 3 in one, stage 4 in two, and stage 5 in one; testicular size was $14.5 \pm 2.5 \mathrm{ml}$. Each

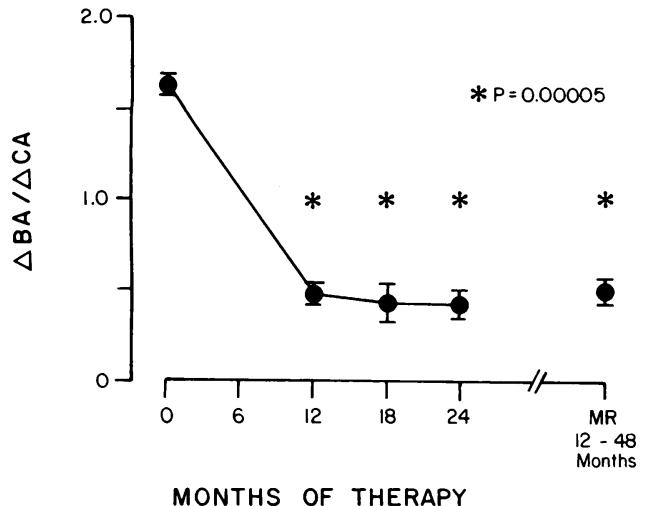

Figure 1. The mean rate of bone maturation for chronologic advancement $(\triangle \mathrm{BA} / \triangle \mathrm{CA})$ before and after 12 to 48 mo of continuous LHRHa administration.

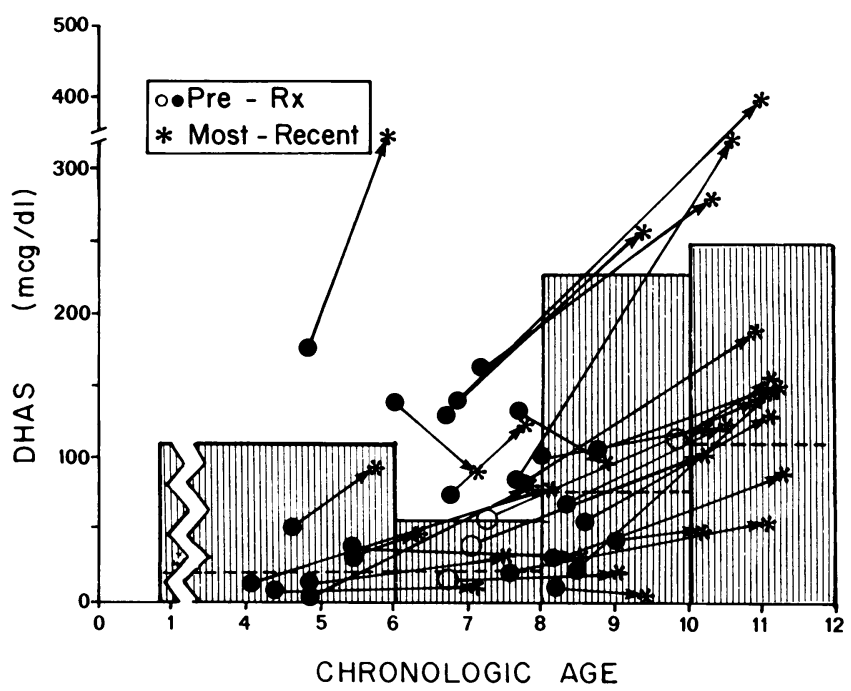

Figure 2. Levels of DHAS in girls ( $\bullet$ ) and boys (O) before (circles) and during (asterisks) 12 to 48 mo of LHRHa administration in relation to CA. Shaded area with dotted line represents the mean \pm 2 SD of the normative data of Reiter et al. (14).

child had experienced a pubertal growth spurt $(9.6 \pm 0.7 \mathrm{~cm} / \mathrm{yr})$ and a rapid rate of bone advancement, so that the ratio of bone age (BA) to CA was $>1$ (Fig. 1), rather than the expected normal ratio of one. Pretherapy $\mathrm{BA}$ ranged from 8 to 13.6 (mean $11.5 \pm 0.3 \mathrm{yr}$ ). Growth velocities were similar in preadrenarchal and adrenarchal children $(10.6 \pm 1.1$ vs. $8.5 \pm 0.7, P=0.11)$.

Despite these manifestations of premature gonadarche, the majority of the children had adrenal androgen levels appropriate for their CA (Fig. 2), but not for their skeletal maturation ( $r$ $=0.02, P=0.92$ ). 10 of 29 children were observed to have DHAS levels outside the normative data base ( $\pm 2 \mathrm{SD}$, Fig. 2 ). The mean age of onset of gonadarche in the children with premature adrenarche was $3.4 \pm 0.8 \mathrm{yr}(n=10)$. Premature activation of the adrenal androgen axis was not correlated with a certain age of onset of the premature sexual maturation (i.e., ages 6-8, as has previously been reported [3]). The presence of pubic hair, as assessed by Tanner staging, did not correlate with DHAS levels before therapy $(r=0.07, P=0.74)$. In fact, three girls aged 4-5 were noted to have pubic hair at Tanner stages 2-3 in association with preadrenarchal DHAS levels $(20.8 \pm 7.8 \mu \mathrm{g} / \mathrm{dl})$.

\section{Post LHRHa therapy}

(1) Gonadal suppression. Table I documents the time interval (12-48 mo) that each child received continuous LHRHa administration. After exposure to LHRHa, each child was noted to have an arrest or regression of the clinical signs of puberty, a

Table I. Number of Children Followed for 12-48 mo of LHRHa Administration

\begin{tabular}{lrrrrrrrr} 
& \multicolumn{8}{l}{ Length of LHRHa administration $(m o)$} \\
\cline { 2 - 8 } & 12 & 18 & 24 & 30 & 36 & 42 & 48 \\
\hline $\begin{array}{l}\text { Number of children } \\
\quad \text { Female }\end{array}$ & 25 & 17 & 17 & 15 & 8 & 3 & 2 \\
$\quad$ Male & 4 & 3 & 3 & 2 & 2 & 1 & 0
\end{tabular}


fall in the mean gonadotropin levels with an ablation of the episodic pattern of secretion, and a return to a prepubertal response to LHRH as previously reported (6-9). Sex steroid levels fell and remained uniformly within the prepubertal range (i.e., testosterone levels on pooled specimens of $15 \pm 2.8 \mathrm{ng} / \mathrm{dl}$ in the males and estradiol levels of $<20 \mathrm{pg} / \mathrm{ml}$ in the females). There were no episodic nocturnal elevations in testosterone levels on frequent sampling (unpublished observations). Slowing of the pubertal growth velocities to prepubertal linear growth rates was achieved ( $24 \mathrm{mo}, 4.1 \pm 0.4$; most recent visit, $4.0 \pm 0.4)$. No differences were observed in growth velocities between preadrenarchal and adrenarchal children $(4.6 \pm 0.4$ vs. $3.8 \pm 0.5, P=0.35)$. Retardation of the accelerated rates of skeletal advancement were also observed during LHRHa therapy, such that the change in bone age $(\triangle \mathrm{BA})$ for change in chronologic age $(\triangle \mathrm{CA})$ fell to less than or equal to one in all patients $(0.49 \pm 0.05)(P=0.00005$, Fig. 1). Before treatment, BA were uniformly greater than CA $(B A / C A=1.7 \pm 0.1)$. The slowing in the rates of epiphyseal maturation was evident by 1 yr of treatment (Fig. 1).

(2) Adrenal maturation. During 12 to 48 mo of LHRHa suppression of gonadarche, DHAS levels, as an index of adrenarche, were constant or increased in an age-expected fashion when compared with normative data (14) (Fig. 2). DHAS values were positively correlated with the degree of pubic hair development after the return of gonadal steroids to prepubertal levels during LHRHa administration, whereas before therapy there had been no correlation due to the inclusion of several patients (see above) in whom pubic hair was present despite preadrenarchal levels of DHAS. This association between DHAS levels and pubic hair development was first evident by 18 mo of treatment ( $r=0.65, P=0.02$ ). In the three girls who exhibited Tanner stage 2-3 pubic hair despite low levels of adrenal androgens, reduction of gonadal steroids to prepubertal levels resulted in a disappearance of the pubic hair.

(3) Skeletal maturation. To assess the effect of adrenal androgens on the rate of skeletal advancement in the absence of pubertal levels of gonadal steroids, levels of DHAS were examined before and after 12 to $48 \mathrm{mo}$ of LHRHa administration. The influence of the adrenarchal status before LHRHa treatment upon the subsequent rate of slowing of bone maturation during therapy was first examined. DHAS values before therapy were predictive of the subsequent rate of slowing of skeletal maturation $(\triangle \mathrm{BA} / \triangle \mathrm{CA})$ during 12 to $48 \mathrm{mo}$ of LHRHa treatment (12 mo, $r=0.63, P=0.001 ; 18 \mathrm{mo}, r=0.79, P=0.001 ; 24 \mathrm{mo}, r$ $=0.73, P=0.001 ;$ most recent visit $(12-48 \mathrm{mo}), r=0.57, P$ $=0.001$, Fig. 3 , top).

To consider the influence of the onset and progression of adrenarche on the rate of skeletal advancement during the LHRHa-induced suppression of gonadal steroids, DHAS values at each follow-up visit were then compared with the bone advancement at that particular interval of time on therapy. During LHRHa administration for 12-48 mo, DHAS levels continued to be significantly correlated with the contemporaneous rate of skeletal maturation $(\triangle \mathrm{BA} / \Delta \mathrm{CA})$ at $12 \mathrm{mo}, r=0.68, P=0.001$; $18 \mathrm{mo}, r=0.73, P=0.001 ; 24 \mathrm{mo}, r=0.54, P=0.02$; and the most recent visit (12-48 mo, $r=0.52, P=0.004$, Fig. 3 , bottom). The children who remained preadrenarchal (DHAS $\leqslant 60 \mu \mathrm{g}$ / dl) during LHRHa suppression of gonadal steroids were noted to have the slowest rate of bone advancement $(\triangle \mathrm{BA} / \Delta \mathrm{CA}$ $=0.34 \pm 0.11$ ). With the onset or progression of adrenal androgen maturation (DHAS $>60$ ), while gonadal steroids were suppressed to normal childhood levels, there was a less pronounced
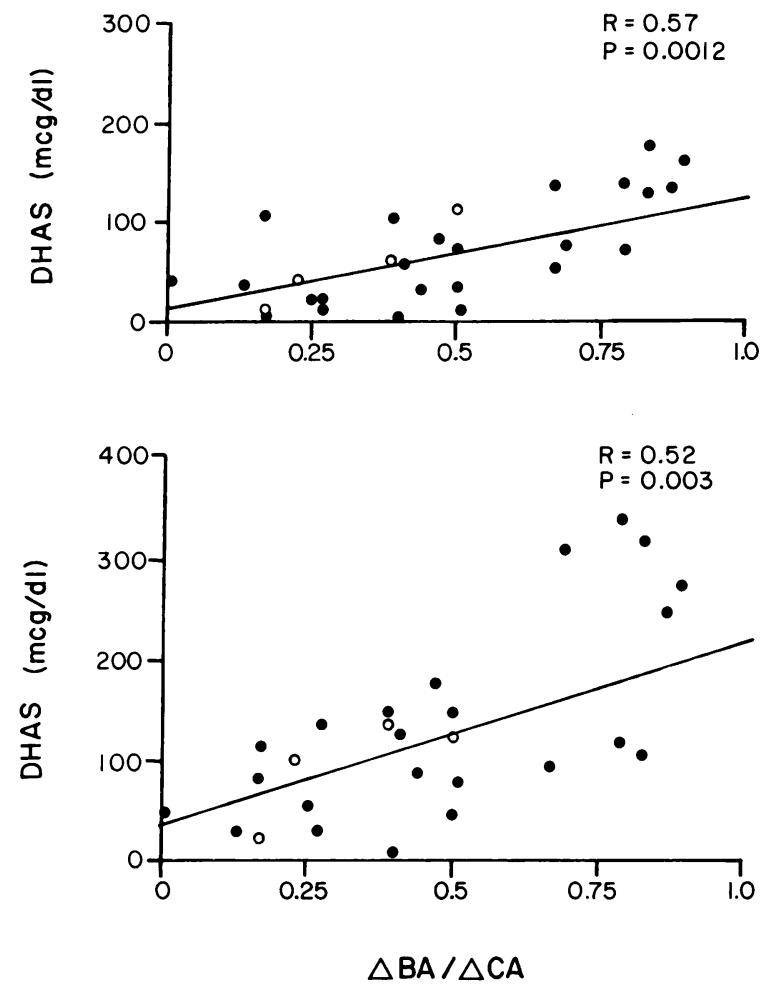

Figure 3. (Top) Pretherapy DHAS levels in girls (๑) and boys (O), related to the rate of bone maturation for chronologic advancement $(\triangle \mathrm{BA} / \triangle \mathrm{CA})$ during the subsequent 12 to $48 \mathrm{mo}$ of LHRHa administration (value at the most recent visit). (Bottom) DHAS levels during 12 to 48 mo of treatment related to the contemporaneous rate of bone maturation for chronologic advancement $(\triangle \mathrm{BA} / \Delta \mathrm{CA})$. Girls (๑); boys (0).

reduction in the rate of skeletal advancement $(\triangle B A / \triangle C A$ $=0.54 \pm 0.05$ ). The difference between the rate of bone maturation in these two subsets of children was statistically significant $(P=0.03)$.

In an attempt to explore the impact of adrenal maturation upon ultimate adult stature, we examined the levels of DHAS in the children before LHRHa administration and their increases in predicted mature height during 12 to 48 mo of LHRHa treatment (Fig. 4). Predicted mature height is calculated from established normative tables (16) and reflects the relationship between skeletal maturation and statural achievement at any given point

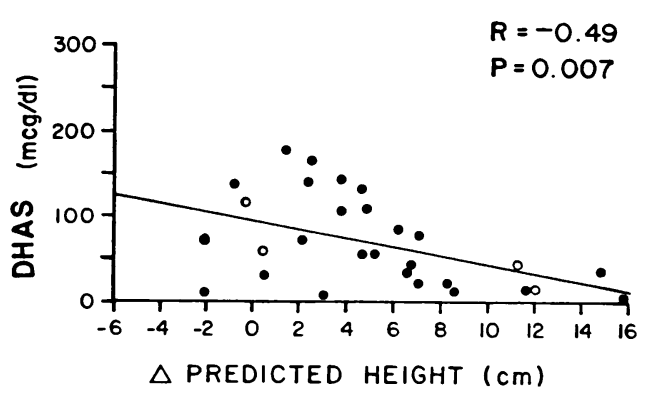

Figure 4. Correlation of pretherapy DHAS levels with the increase in predicted mature height during the subsequent $12-48$ mo of LHRHa administration (value at the most recent visit). Girls (๑); boys (0). 
in time. Increases in predicted height occur whenever statural growth progresses at a more rapid rate than that ordinarily expected for the child's skeletal maturation. DHAS values before LHRHa administration were negatively correlated with the increment in predicted height occurring during suppression of gonadal steroids. This relationship was observed at $12 \mathrm{mo}, r$ $=0.36, P=0.05 ; 18 \mathrm{mo}, r=-0.47, P=0.04 ; 24 \mathrm{mo}, r=-0.53$, $P=0.02$; and at the most recent visit (12-48 mo, $r=-0.49, P$ $=0.007$ ). Four children had a diminution in predicted height during therapy (mean, $1.6 \mathrm{~cm}$ ). Three of four of these children had premature adrenarche, and all had been on LHRHa therapy less than the mean length of the entire group (1.6 vs. $2.35 \mathrm{yr}$ ).

Thus, the children who were preadrenarchal before LHRHa treatment (i.e., DHAS $\leqslant 60$ ) had the largest increment in predicted mature height during continuous LHRHa-induced blockade of gonadal steroids. Those children who were already adrenarchal before LHRHa exposure were observed to have a less striking increase in predicted adult stature during the 1248 mo of treatment.

\section{Discussion}

The multiple factors influencing adrenal androgen secretion have not yet been clarified. In addition to the known influence of ACTH upon adrenal androgen secretion (17-19), investigators recently have postulated the existence of a separate trophic factor to explain the many situations in which a disassociation occurs between glucocorticoid and adrenal androgen secretion $(20,21)$.

Previous attempts to dissect the interactions between adrenal and gonadal steroids have relied upon careful observation of experiments of nature. Albright reported that the appearance of pubic and axillary hair as well as a peripubertal rise in $17 \mathrm{ke}-$ tosteroid levels were markers of adrenal androgen maturation and were present in agonadal subjects (1). Using serum levels of DHAS because of its long serum half-life as a stable index of adrenal androgen secretion, Sklar et al. (3) documented that subjects with gonadal dysgenesis have levels of DHAS that do not differ significantly from those of control subjects with intact gonads. These investigators also confirmed the previous observation by Copeland et al. (2) that patients with idiopathic hypogonadotropic hypogonadism (isolated LHRH deficiency) experienced adrenarche despite absent gonadarche, in contrast to boys with constitutional delay in whom both adrenarche and gonadarche were delayed. In children with premature pubarche $(4,5)$, early activation of adrenal androgen secretion has been reported in the presence of prepubertal gonadal steroid levels. In concert, these studies have suggested the independent control of adrenal and gonadal steroid secretion.

Our study extends these observations by examining the aforementioned relationships in a controlled, experimental paradigm. Measurements of DHAS levels were used as an index of adrenarche because the hormone has a long serum half-life and is the only androgen that is primarily secreted by the adrenal $(>95 \%)$. A small contribution by the gonad, an enzyme defect, or a maturational change in steroid metabolism (in the four boys) is highly unlikely, but cannot be excluded. There are no data to suggest that the LHRHa would act to increase DHAS secretion from the adrenal or gonad. In humans, the analogue appears to have a direct pituitary effect selectively suppressing gonadotropin secretion (22).

Employing the DHAS level as an index of adrenarchal status, we were able to follow the ontogeny of adrenal androgen secretion during a 12-48-mo period when the gonadal steroid milieu of children with central precocity was selectively returned to a prepubertal state. During this time, DHAS values were appropriate for CA although not for the degree of skeletal maturation. In the prepubertal sex steroid environment induced by LHRHa administration, adrenarche began and progressed in an age-expected fashion. Thus, premature activation of the hypothalamicpituitary-gonadal axis does not appear to be associated with premature activation of the hypothalamic-pituitary-adrenal axis in most children with central precocity.

Previous investigators have suggested that precocious gonadarche may be triggered by precocious adrenarche $(23,24)$. Sklar et al. (3) observed increased levels of DHAS compared with age-matched controls when the precocity began between CAs 6-8, but not when the precocity began before age 6.10 of our 29 children were noted to have precocious adrenarche. In contrast to the previous report, the age of onset of sexual precocity in our study was not associated with the occurrence of premature adrenarche, and many of the 10 subjects with premature adrenarche noted the onset of their gonadarche before age 6. This observation suggests that neither one of these generally age-dependent processes triggers the onset of the other.

Having established that LHRHa is capable of maintaining prepubertal levels of gonadal sex steroids without influencing the normal ontogeny of adrenal androgen secretion, the effects of increasing adrenal androgen levels upon epiphyseal maturation could then be examined. An influence of adrenal sex steroids upon epiphyseal maturation has been previously inferred from observations in three clinical settings. Cases of virilizing adrenal adenomas and carcinomas presenting in childhood have been associated with striking degrees of skeletal advancement (2528). Additionally, children with congenital adrenal hyperplasia have been observed to have BA that may become greatly advanced for CA $(29,30)$. These situations, however, are problematic experimental models because of the nonphysiologic levels of adrenal androgens which are present.

Patients with an isolated deficiency of gonadotropin-releasing hormone are a third subset in which it is possible to chronicle the progression of adrenarche independent from that of gonadarche. While detailed data concerning the timing and pace of their adrenal maturation are not available, descriptions of the natural history of these patients intimate that their growth plates often fuse in the absence of gonadal steroids, suggesting a potential role for adrenal steroids in epiphyseal maturation (31, 32). However, as recent investigations have delineated the clinical and biochemical heterogeneity of patients with this disorder (33), it has become evident that these patients constitute a less than optimal model in which to study of the isolated effects of adrenal androgens upon the rate of bone maturation.

Experimental models in which exogenous adrenal androgens have been administered have been contradictory. Dehydroepiandrosterone was observed to increase the rate of skeletal maturation in infant and prepubertal mice in a manner equivalent to testosterone (34). The dosages used, however, were nonphysiologic, and the exogenously administered DHAS may well have been converted to testosterone. In the human, Forest et al. (35) administered DHAS to children with delayed or absent adrenarche in physiologic doses for up to 24 mo without demonstrable effects upon epiphyseal advancement.

Using a paradigm in which a prepubertal gonadal steroid milieu is restored experimentally while adrenarche begins and 
progresses in a normal fashion, our study confirms and extends previous clinical observations and documents the association between increasing levels of adrenal androgens and accelerated rates of skeletal maturation during childhood. Children who remained preadrenarchal during LHRHa suppression of gonadarche exhibited the greatest slowing of their previously rapid rates of skeletal maturation. With the onset of progression of adrenarche when gonadal steroids were restored to prepubertal levels, a less striking slowing of bone maturation was observed. The subjects who were preadrenarchal at the onset of LHRHa administration and remained so throughout treatment were observed to have the more striking retardation in the rates of skeletal advancement and, consequently, the larger increments in their predicted adult heights. Linear growth rates were not correlated with adrenarchal status; however, the impact of adrenal androgens upon linear growth would be difficult to assess in our study in relation to the impact of other factors such as CA, skeletal age, growth hormone status, and a child's genetic program of statural growth.

Contrary to a clinical teaching that pubic hair is the major clinical marker of adrenal androgen secretion (at least in females) $(1,36,37)$, our data suggest that the control of hormonally mediated hair growth is more complex. Some of the girls with premature gonadarche had pubic hair without evidence of adrenal activation and, when their gonadal steroids were suppressed, the hair disappeared without a change in the levels of DHAS. This suggested that the hormonal support for their pubic hair was related either to gonadal androgens or to estrogen-induced potentiation of the low levels of androgens present. When the pubertal levels of gonadal steroids subsequently declined to prepubertal concentrations with LHRHa administration, the correlation of DHAS levels with the degree of development of pubic hair was restored. These observations imply a complicated and as yet poorly understood influence of the local sex steroid environment on the growth of the hair follicle. Perhaps, in addition to the type of sex steroid and its concentration, there is a component of temporal exposure that modifies the impact of the hormonal stimulus upon sexual hair growth.

In summary, LHRHa administration permits a dissection of the influences of a normal ontogeny of adrenal androgen secretion during childhood from those of gonadarche. Use of this selective probe resulted in sustained suppression of gonadarche in children with CPP, restoring a prepubertal gonadal steroid milieu for 12-48 mo. It appears that this approach provides independent support for previous observations, which suggest that adrenarche and gonadarche are independent processes. In addition, these data suggest that the growth of pubic hair may be influenced by gonadal as well as adrenal steroids, and demonstrate that adrenal androgens contribute to epiphyseal maturation during childhood. It is likely that LHRHa administration will prove most effective in increasing the predicted mature height of children with precocity who are preadrenarchal. The role of adrenal androgens in statural growth during mid-childhood and in the adolescent growth spurt remains to be elucidated by future investigation.

\section{Acknowledgments}

We gratefully acknowledge the technical assistance and support of Barbara Hedges, Karin Karol, Birgit Keller, Steve Trigilio, Jacquelyn R. Donnelly, Nancy Delaney-Perry, Carole Thompson, the nurses of the Clinical Re- search Centers of the Massachusetts General Hospital and the Children's Hospital, and to Drs. Wylie Vale and Jean Rivier for their generous gift of the LHRHa.

This work was supported in part by grant R01-HD 18169 from the National Institutes of Health.

\section{References}

1. Albright, F., P. H. Smith, and R. Fraser. 1942. A syndrome characterized by primary ovarian insufficiency and decreased statute: report of 11 cases with digression on hormonal control of axillary and pubic hair. Am. J. Med. Sci. 204:625-648.

2. Copeland, K. C., L. Paunier, and P. C. Sizonenko. 1977. The secretion of adrenal androgens and growth patterns of patients with hypogonadotropic hypogonadism and idiopathic delayed puberty. J. Pediatr. 91:985-990.

3. Sklar, C. A., S. L. Kaplan, and M. M. Grumbach. 1980. Evidence for dissociation between adrenarche and gonadarche: studies in patients with idiopathic precocious puberty, gonadal dysgenesis, isolated gonadotropin deficiency, and constitutionally delayed growth and adolescence. J. Clin. Endocrinol. Metab. 51:548-556.

4. Korth-Schutz, S., L. S. Levine, and M. I. New. 1976. Evidence for the adrenal source of androgen in precocius adrenarche. Acta Endocrinol. 82:342-352.

5. Rosenfield, R. L., B. H. Rich, and A. W. Lucky. 1982. Adrenarche as a cause of benign pseudopuberty in boys. J. Pediatr. 101:1005-1009.

6. Crowley, W: F., F. Comite, W. Vale, J. Rivier, D. L. Loriaux, and G. B. Cutler. 1981. Therapeutic use of pituitary desensitization with a long-acting LHRH agonist: a potential new treatment for idiopathic precocious puberty. J. Clin. Endocrinol. Metab. 52:370-372.

7. Comite, F., G. B. Cutler, J. Rivier, W. W. Vale, D. L. Loriaux, and W. F. Crowley. 1981. Short-term treatment of idiopathic precocious puberty with a long-acting analogue of luteinizing hormone-releasing hormone. N. Engl. J. Med. 305:1546-1550.

8. Mansfield, M. J., D. E. Beardsworth, J. S. Loughlin, J. D. Crawford, H. H. Bode, J. Rivier, W. Vale, D. C. Kushner, J. F. Crigler, and W. F. Crowley. 1983. Long-term treatment of central precocious puberty with a long-acting analogue of luteinizing hormone-releasing hormone. $N$. Engl. J. Med. 309:1286-1290.

9. Wierman, M. E., M. A. Beardsworth, M. J. Mansfield, T. M. Badger, J. D. Crawford, J. F. Crigler, H. H. Bode, J. S. Loughlin, D. C. Kushner, R. E. Scully, W. H. Hoffman, and W. F. Crowley. Puberty without gonadotropins-a unique mechanism of sexual development. N. Engl. J. Med. 312:65-72.

10. Tanner, J. M. 1962. Growth at Adolescence. Second ed. Charles C. Thomas, Springfield, IL.

11. Zachman, M., A. Prader, H. P. Kind, H. Haflinger, and H. Budlinger. 1974. Testicular volume during adolescence. Helv. Paediatr. Acta. 29:61-72.

12. Hoffman, A. R., and W. F. Crowley. 1982. Induction of puberty in men by long-term pulsatile administration of low-dose gonadotropinreleasing hormone. N. Engl. J. Med. 307:1237-1241.

13. Buster, J. E., and G. E. Abraham. 1972. Radioimmunoassay of plasma dehydroepiandrosterone sulfate. Anal. Lett. 5:543-51.

14. Reiter, E. O., V. G. Fuldauer, and A. W. Root. 1977. Secretion of the adrenal androgen, dehydroepiandrosterone sulfate, during normal infancy, childhood, and adolescence, in sick infants, and in children with endocrinologic abnormalities. J. Pediatr. 90:766-770.

15. Greulich, W. W., and S. I. Pyle. 1959. Radiographic Atlas of Skeletal Development of the Hand and Wrist. Second ed. Standford University Press, Stanford. 1-256.

16. Bayley, N., and S. R. Pinneau. 1952. Tables for predicting adult height from skeletal age: revised for use with the Greulich-Pyle hand standards. J. Pediatr. 40:423-441.

17. Schiebinger, R. J., B. D. Albertson, F. G. Cassorla, D. W. Bowyer, G. W. Geelhoed, G. B. Cutler, and D. L. Loriaux. 1981. The developmental changes in plasma adrenal androgens during infancy and adren- 
arche are associated with changing activities of adrenal microsomal 17 hydroxylase and 17,20-desmolase. J. Clin. Invest. 67:1177-1182.

18. Rich, H., R. L. Rosenfield, R. L. Lucky, and J. C. Helke. 1980. Adrenarche: changing adrenal response to adrenocorticotropin. J. Clin. Endocrinol. Metab. 52:1129-1136.

19. Anderson, D. C. 1980. The adrenal androgen-stimulating hormone does not exist. Lancet. ii:454-456.

20. Parker, L. N., and W. D. Odell. 1979. Evidence for existence of cortical androgen-stimulating hormone. Am. J. Physiol. 236:E616-E620.

21. Parker, L. N., E. T. Lifrak, and W. D. Odell. 1983. A 60,000 molecular weight human pituitary glycopeptide stimulates adrenal androgen secretion. Endocrinology. 113:2092-2096.

22. Clayton, R. N. 1982. Absence of gonadotropin releasing hormone receptors in human gonadal tissue. Nature (Lond.). 299:56-59.

23. Ducharme, J. R., M. G. Forest, E. DePeretti, M. Sempe, R. Collu, and J. Bertrand. 1976. Plasma adrenal and gonadal sex steroids in human pubertal development. J. Clin. Endocrinol. Metab. 42:468-476.

24. Collu, R., and J. R. Ducharme. 1975. Role of adrenal steroids in the regulation of gonadottopin secretion at puberty. J. Steroid Biochem. 6:869-872.

25. Hutter, A. M., Jr, and D. E. Kayhoe. 1966. Adrenal cortical carcinoma: clinical features of 138 patients. Am. J. Med. 41:572-580.

26. Kenny, F. M., Y. Hashida, H. A. Askari, W. H. Wieber, and G. H. Fetterman. 1968. Virilizing tumors of the adrenal cortex. Am. J. Dis. Child. 115:445-458.

27. Castleman, B., R. E. Scully, and B. U. McNeely. 1972. Case records of the Massachusetts General Hospital. N. Engl. J. Med. 287: 1033-1040.

28. Gabrilove, J. L., A. T. Seman, H. A. Mitty, and G. L. Nicolis. 1981. Virilizing adrenal adenoma with studies on the steroid content of the adrenal venous effluent and a review of the literature. Endocrine Reviews. 2:462-470.

29. Klingensmith, G. J., S. C. Garcia, H. W. Jones, Jr., C. J. Migeon, and R. M. Blizzrd. 1977. Glucocorticoid treatment of girls with congenital adrenal hyperplasia: effects on height sexual maturation, and fertility. $J$. Pediatr. 90:996-1004.

30. Kirkland, R. T., B. S. Keenan, J. H. Holcombe, J. L. Kirkland, and G. W. Clayton. 1978. The effect of therapy on mature height in congenital adrenal hyperplasia. J. Clin. Endocrinol. Metab. 47:13201324.

31. Kaushanski, A., and Z. Laron. 1979. Growth pattern of boys with isolated gonadotropin deficiency. Israel J. Med. Sci. 15:518-52i.

32. Cohen, H. N., G. H. Beastall, A. M. Wallace, I. Fogelman, and J. A. Thomson. 1981. Clinical values of adrenal androgen measurement in the diagnosis of delayed puberty. Lancet. i:681-692.

33. Crowley, W. F., M. Filicori, D. I. Spratt, and N. F. Santoro. 1985. The physiology of gonadotropin-releasing hormone (GnRH) secretion in men and women. Recent Prog. Horm. Res. 41:473-531.

34. Howard, E. 1963. Effects of steroids on epiphyseodiaphyseal union in prepubertal mice. Endocrinology. 72:11-18.

35. Forest, M. G., E. dePeretti, M. David, and M. Sempe. 1982. L'Adrenarche joue-t-elle vraiment un role determinant dans le developpement pubertaire? Etude des dissociations entre adrenarche et gonadarche. Echec tu traitement par la dehydroepiandrosterone sulphate dans les retards d'adrenarche. Ann. Endocrinol. (Paris). 43:465-495.

36. Speroff, L., R. H. Glass, and N. G. Kase, editors. 1983. Clinical gynecologic endocrinology and infertility. Third ed. Williams \& Wilkens, Baltimore. 364.

37. Grumbach, M. M. 1978. The central nervous system and the onset of puberty. In Human Growth. F. Falkner and J. M. Tanner, editors. Plenum Press, NY. 2:233-235. 